\title{
Phase I study of samalizumab in chronic lymphocytic leukemia and multiple myeloma: blockade of the immune checkpoint CD200
}

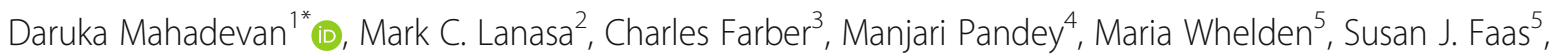
Terrie Ulery ${ }^{5}$, Anjli Kukreja ${ }^{5}$, Lan Li ${ }^{5}$, Camille L. Bedrosiann, Xiaoping Zhang ${ }^{5}$ and Leonard T. Heffner ${ }^{6}$

\begin{abstract}
Purpose: Samalizumab is a novel recombinant humanized monoclonal antibody that targets CD200, an immunoregulatory cell surface member of the immunoglobulin superfamily that dampens excessive immune responses and maintains self-tolerance. This first-in-human study investigated the therapeutic use of samalizumab as a CD200 immune checkpoint inhibitor in chronic lymphocytic leukemia (CLL) and multiple myeloma (MM).

Experimental design: Twenty-three patients with advanced CLL and 3 patients with MM were enrolled in an openlabel phase 1 study (NCT00648739). Patients were assigned sequentially to one of 7 dose level cohorts (50 to $600 \mathrm{mg} / \mathrm{m}^{2}$ ) in a $3+3$ study design, receiving a single dose of samalizumab intravenously once every 28 days. Primary endpoints were safety, identification of the maximum tolerated dose (MTD), and pharmacokinetics. Secondary endpoints were samalizumab binding to CD200, pharmacodynamic effects on circulating tumor cells and leukocyte subsets, and clinical responses.

Results: Twenty-one patients received $>1$ treatment cycle. Adverse events (AEs) were generally mild to moderate in severity. Samalizumab produced dose-dependent decreases in CD200 expression on CLL cells and decreased frequencies of circulating CD200 + CD4+ T cells that were sustained at higher doses. The MTD was not reached. Decreased tumor burden was observed in $14 \mathrm{CLL}$ patients. One CLL patient achieved a durable partial response and 16 patients had stable disease. All MM patients had disease progression.
\end{abstract}

Conclusions: Samalizumab had a good safety profile and treatment was associated with reduced tumor burden in a majority of patients with advanced CLL. These preliminary positive results support further development of samalizumab as an immune checkpoint inhibitor.

Trial registration: ClinicalTrials.gov, NCT00648739 registered April 1, 2008.

Keywords: CLL, Multiple myeloma, CD200, Immune checkpoint inhibitor, Samalizumab

\footnotetext{
* Correspondence: DMahadevan@uacc.arizona.edu

'Department of Medicine Division of Hematology/Oncology, University of Arizona Cancer Center, 1515. N. Campbell Avenue, Room 1905, Tucson, AZ 85724, USA

Full list of author information is available at the end of the article
}

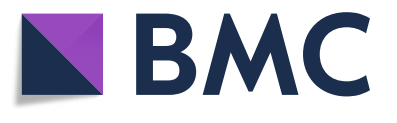

(c) The Author(s). 2019 Open Access This article is distributed under the terms of the Creative Commons Attribution 4.0 International License (http://creativecommons.org/licenses/by/4.0/), which permits unrestricted use, distribution, and reproduction in any medium, provided you give appropriate credit to the original author(s) and the source, provide a link to the Creative Commons license, and indicate if changes were made. The Creative Commons Public Domain Dedication waiver (http://creativecommons.org/publicdomain/zero/1.0/) applies to the data made available in this article, unless otherwise stated. 


\section{Introduction}

CD200 and CD200 receptor (CD200R) are highly conserved type I paired membrane glycoproteins, consisting of two immunoglobulin (Ig)-like domains (V and $\mathrm{C}$ ) that belong to the Ig protein superfamily [1-3]. CD200 is widely expressed on a variety of cell types, including $\mathrm{B}$ cells, a subset of $\mathrm{T}$ cells, dendritic cells, endothelial, neuronal and other cells, while CD200R expression is largely limited to subsets of T cells and myeloid lineage cells [3-7]. The ligation of CD200 with its receptor, CD200R, imparts a multipronged immunosuppressive signal, potently inhibiting $\mathrm{T}$-cell immune responses and natural killer (NK) cytotoxic activity, promoting macrophage secretion of indoleamine-2,3 dioxygenase (IDO), an immunosuppressive tryptophan-catabolizing enzyme, and triggering regulatory $\mathrm{T}$ cell $\left(\mathrm{T}_{\mathrm{reg}}\right)$ expansion [8-12]. The immune checkpoint function of CD200 on dendritic cells and lymphoid effector cells modulates the activation threshold of inflammatory immune responses and contributes to the maintenance of self-tolerance [13].

CD200 is overexpressed in a wide variety of solid and hematological tumor cell types, including chronic lymphocytic leukemia (CLL) multiple myeloma (MM), acute myeloid leukemia (AML) and others, and is also expressed at elevated levels on cancer stem cells [14-18]. McWhirter et al. first showed that primary tumor cells from CLL patients overexpress CD200 compared with expression on normal B cells [14].

Dampened anti-tumor cytotoxic T cell (CTL) responses are associated with the overexpression of immune checkpoints including CD200, cytotoxic T lymphocyte antigen4 (CTLA-4) and programmed death-1 (PD-1) on tumor, immune and stromal cells within the tumor microenvironment, and the consequent immunoregulatory signaling events following binding to their respective ligands or receptors [19-21]. Down-regulation of allogeneic Type 1 $\mathrm{T}$ helper (Th1) responses, as measured by decreases in interleukin-2 (IL-2) and interferon-gamma (IFN- $\gamma$ ), was noted following the addition of primary CLL cells to an in vitro mixed lymphocyte reaction, and anti-CD200 antibodies reversed this effect, restoring Th1 responses and suppressing $\mathrm{T}_{\text {regs }}[14,16,22,23]$. In syngeneic and xenograft murine models, treatment with anti-CD200 antibodies restored lymphocyte mediated anti-tumor responses in vivo [23, 24].

In addition to immunosuppression, overexpression of CD200 on tumor cells has been correlated with aggressive tumor progression, greater metastatic potential, and reduced patient survival, which suggests that CD200 is a promising target for cancer immunotherapy [15, 25]. Accumulated evidence supports the rationale for developing therapeutic anti-CD200 antibodies lacking effector function to block CD200-CD200R-mediated signaling while preserving immune components critical for anti- tumor immunity such as activated $\mathrm{T}$ cells and dendritic cells [26]. Blockade of various immune checkpoints, alone or in combination, to reverse T-cell mediated immune suppression and activate anti-tumor immunity is a promising approach to treating cancers [19-21, 27]. Durable clinical responses, including enhanced survival, have been reported with therapeutic blockade of CTLA-4 with ipilimumab, and of PD-1 with pembrolizumab and nivolumab in patients with melanoma, non-small cell lung cancer, renal cancer and head and neck squamous cell carcinoma, leading to FDA approvals [28-35]. Combination therapy blocking both CTLA-4 and PD-1 is now approved for melanoma. Other combinations of targeted therapies, immune checkpoint inhibitors and activators that enhance innate immunity are also being evaluated [36-40].

Samalizumab is a novel recombinant, humanized monoclonal antibody (mAb) that specifically binds to CD200 and blocks its ligation to the CD200 receptor (CD200R). Samalizumab was rationally engineered with an Ig G2/G4 constant region to minimize effector function and preserve immune cell subsets [26].

This is a first-in-human phase I trial to evaluate the safety, pharmacokinetics (PK), pharmacodynamic (PD), and anti-tumor activity of CD200 blockade with samalizumab in patients with CLL and MM, and to identify the maximum tolerated dose (MTD) and dose-limiting toxicity (DLT) of samalizumab.

\section{Methods}

\section{Eligibility and study schema}

This was an open-label, multi-center, sequential cohort dose escalation study (June 2008 - Dec. 2010). The primary endpoints were safety, identification of MTD, and characterization of PK. Secondary endpoints were samalizumab binding to CD200, PD effects on circulating tumor cells and leukocyte subsets, and clinical responses to treatment. The study was conducted in accordance with the Declaration of Helsinki and principles of the International Conference on Harmonisation guidelines on Good Clinical Practice.

Patients with relapsed or refractory CLL or MM, defined as either having failed or refractory to at least one approved therapeutic agent, or who declined standard treatment options, were eligible. Additional inclusion criteria included an Eastern Cooperative Oncology Group performance status score of $0-2$ and anticipated survival of $>6$ months. Patients were excluded from the study if they met any of the following criteria: absolute neutrophil count $<1000 \times 10^{9} / \mathrm{L}$, platelet count $<50,000 \times 10^{9} / \mathrm{L}$; pregnant or lactating; prior history of autoimmune hemolysis; immune thrombocytopenia; active autoimmune disease requiring immunosuppressive therapy; positive Coombs' test; chronic infection with HBV, HCV or HIV; ongoing corticosteroid treatment equivalent to $\geq 10 \mathrm{mg} /$ day 
of prednisone; prior stem cell transplantation or prior chemotherapy within 4 weeks or 30 days of enrollment, respectively; neurosurgery or cranial radiotherapy within one year of enrollment; serum creatinine $>1.5$ times upper limit of normal, alanine amino transferase or aspartate amino transferase $>2.5$ times upper limit of normal, cardiopulmonary disease (New York Heart Association Functional Class III or IV); active systemic bacterial or fungal infection; prior therapy with another investigational product within 30 days of screening; or any condition that could increase the patient's risk or confound outcome, at the investigators' discretion.

Patients were assigned sequentially to one of 7 dose level cohorts following a $3+3$ study design: $50 \mathrm{mg} / \mathrm{m}^{2}$, $100 \mathrm{mg} / \mathrm{m}^{2}, 200 \mathrm{mg} / \mathrm{m}^{2}, 300 \mathrm{mg} / \mathrm{m}^{2}, 400 \mathrm{mg} / \mathrm{m}^{2}, 500 \mathrm{mg} / \mathrm{m}^{2}$ or $600 \mathrm{mg} / \mathrm{m}^{2}$. Each patient only received the dose to which they were assigned. The first dose day was considered as cycle 1, day 0 . Patients who tolerated the study drug and had at least stable disease at six weeks following the first dose were permitted to continue therapy until they experienced disease progression, toxicity, or if the investigator or patient wished to discontinue therapy. Additional dosing cycles at the same dose were added as one dose per 28-day cycle, beginning no sooner than six weeks after the initial dose.

At least three patients were assigned per cohort; if none experienced a DLT, escalation to the next dose level occurred with a new cohort. A DLT was defined as any grade 3 or greater toxicity, according to the NCI Common Terminology Criteria for Adverse Events (CTCAE) version 3.0, (NCI 2006) occurring in the first 28 days after dosing in cycle 1 . Patients were followed for 10 weeks after their last dose with safety, PK, PD, anti-tumor and clinical response evaluations.

Baseline evaluations for all patients included medical history, physical examination, ophthalmologic slit lamp examination, $\mathrm{CBC}$ and differential, chemistry and thyroid panels, electrocardiogram (ECG), hepatitis and HIV serology, Coombs' test, anti-drug antibody (ADA), coagulation panel, and bone marrow biopsy (optional). CT scans were performed in all CLL patients, while MM patients were evaluated for beta-2 microglobulin, serum protein electrophoresis, serum free light chain and ratio, $24 \mathrm{~h}$ urine for total protein and urine protein electrophoresis, serum viscosity, and skeletal survey. See Additional file 1 for further information on dosing and clinical laboratory assays.

\section{Safety and tolerability}

The safety and tolerability of samalizumab in the study patient population were assessed by treatment-emergent adverse events (TEAEs), treatment-emergent serious adverse events (SAEs), clinical laboratory evaluations, vital signs, ECG, and physical and ophthalmology slit lamp examinations.

\section{Pharmacokinetic assessment}

Blood samples for PK analyses in cycle 1 were collected at pre-dose on day $0(0 \mathrm{~h})$ and at $0.5 \mathrm{~h}$, end of infusion, and $8,24,48,72,168,240,336,672$, and $1008 \mathrm{~h}$ after the start of the infusion. Estimated PK parameters for samalizumab, derived from serum concentration-time curves, were total clearance (CL), maximum concentration $\left(C_{\max }\right)$, time to reach $C_{\max }\left(T_{\max }\right)$, terminal elimination half-life $\left(\mathrm{T}_{1 / 2}\right)$, volume of distribution based on terminal elimination phase $\left(\mathrm{V}_{\mathrm{z}}\right)$, and area under the serum concentration-time curve from time zero extrapolated to infinity $\left(\mathrm{AUC}_{\infty}\right)$. $\mathrm{PK}$ parameters were estimated using non-compartmental methods with WinNonlin ${ }^{\circ}$ (Version 6.4, Pharsight Corporation, Menlo Park, CA). See Additional file 1 for methodologic details.

\section{Pharmacodynamic assessment}

Blood samples for the measurement of PD markers in cycle 1 were collected pre-dose on day 0 , and post-dose on days $1,7,14,24$, and 42; during cycles 2 to 4 , PD assessments were evaluated pre-dose and on day 14 . Samalizumab binding to CD200 on circulating CLL cells was evaluated by multi-parametric flow cytometry using a fluorescently-labeled mAb specific for samalizumab together with a second anti-CD200 mAb specific for an epitope of CD200 distinct from the binding site of samalizumab. CD200 and CD200R expression on peripheral T-cell subsets (CD3+, CD4+, CD8+, activated T cells, $\mathrm{T}_{\text {regs }}$ ) collected from CLL and MM patients were evaluated by immunofluorescence and flow cytometry. Data were analyzed as percent of CD200+ cells within the indicated population as well as by mean channel fluorescence intensity (MFI) of bound antibody to reflect the CD200 density on CD200+ cells. See Additional file 1 for methodologic details.

\section{Cytokine assessment}

Serum from patients was evaluated for interleukin (IL)$1 \beta$ (IL-1 $\beta)$, IL-2, IL-4, IL-6, IL-10, IL-12p70, IFN- $\gamma$ and tumor necrosis factor alpha (TNF- $\alpha)$ pre-dose and at various times post-dose through week 10 (See Additional file 1 for methodologic details).

\section{Anti-tumor assessment}

Clinical responses were based on the Modified NCI Working Group Response Criteria for CLL [41] and on the International Myeloma Working Group Uniform Response Criteria for MM [42]. For CLL, the overall response rate (ORR) was defined as the percentage of patients who maintained their best response for at least one month after achieving that best response and having 
either a complete response (CR), partial response (PR), nodular partial response (nPR), or stable disease (SD). Progressive disease (PD) was defined by one of the following: $>50 \%$ increase in the sum of the products of at least two lymph nodes (at least one lymph node must be $>2 \mathrm{~cm}$ ), appearance of new lymph nodes, $>50 \%$ increase in the size of the liver and/or spleen, $>50 \%$ increase in the absolute number of circulating lymphocytes to at least $5000 / \mathrm{uL}$, or transformation to a more aggressive histology (Richter's Syndrome). For MM, ORR was defined as the percentage of patients who had SCR (stringent CR), CR, very good partial response (VGPR), or PR on two consecutive assessments made at any time before the administration of any new therapy. PD was defined as $>25 \%$ increase of urine $\mathrm{M}$-protein.

Computed tomography (CT) scans of the neck, chest, abdomen, and pelvis in CLL patients were evaluated using sum of the products of bi-dimensional measurements of all target lesions [41], Additional cycles of treatment were continued if there was evidence of response by blood counts or physical exam at weeks 4 and 8. Anti-tumor responses were evaluated as the percent change from baseline in lymphadenopathy.

\section{Statistical analyses}

Patients who received at least one dose of samalizumab were included in safety, PK, PD, and clinical responseanalyses. Data collected at all sites were pooled for analysis, and descriptive statistics were used to summarize the data. All tables and listings were generated using $\mathrm{SAS}^{\circ}$ Version 9.2 or higher (SAS Institute, Inc., Cary, NC).

\section{Results}

\section{Patient disposition and treatment exposure}

Twenty-six patients, 23 with CLL (4 were treatment naïve) and 3 with MM, were enrolled from June 2008 to December 2010 across four study sites. Patient characteristics are given in Table 1 . All 26 patients received at least one samalizumab dose. The clinical study was amended to allow multiple doses of samalizumab to be administered. Twenty-one patients $(81 \%)$ received multiple dosing cycles and five patients (19\%), including two MM patients, received one dose. Thirteen patients (50\%) received $\geq 4$ cycles of samalizumab. The maximum number of cycles received by any patient was $18\left(300 \mathrm{mg} / \mathrm{m}^{2}\right.$ dose cohort). The study was terminated prematurely by the sponsor for administrative reasons. Data from all 26 patients were analyzed except where noted.

\section{Safety and adverse events}

The MTD was not reached, and administration of samalizumab from 50 to $600 \mathrm{mg} / \mathrm{m}^{2}$ was well-tolerated in patients with CLL or MM. Only one patient was treated with the $600 \mathrm{mg} / \mathrm{m}^{2}$ dose; this patient (with MM) did not complete the study and died of progressive disease shortly after two weeks of follow-up. A total of 256 TEAEs were reported by 25 (96\%) patients; the most commonly reported TEAEs are listed in Table 2. Five patients experienced TEAEs that were deemed possibly, probably, or definitely related to study drug that were grade 3-4 in severity. The most common drug-related grade 3-4 TEAEs were blood and lymphatic system disorders (anemia, neutropenia, and thrombocytopenia) reported in three patients (12\%). The other drug-related grade 3-4 TEAEs were reduced visual acuity and muscular weakness (both in the same patient, $4 \%$ ), respiratory syncytial virus infection (1 patient, $4 \%$ ), and rash (1 patient, 4\%) (Table S1). TEAEs that were considered definitely related to the study drug occurred in two of three patients with elevated ADA at the time of samalizumab administration: hypersensitivity (grade 1 allergic reaction) and urticaria (grade 2 hives).

Of the 26 study participants, six (23\%) experienced at least one SAE; four (15\%) had SAEs considered unrelated to study drug and two (8\%) had SAEs considered possibly related to study drug. One fatal SAE, due to complications post-elective cholecystectomy and ensuing renal failure, occurred 23 days after the fourth dose of $100 \mathrm{mg} / \mathrm{m}^{2}$. The investigators determined that the event was unrelated to samalizumab. No SAEs led to discontinuation.

In some patients, ECGs revealed heart rate, PR interval, QRS duration and QTc intervals outside normal ranges on occasion, but these were not clinically significant events. In aggregate, no QT interval changes were observed. No significant ophthalmologic findings were attributed to samalizumab treatment.

\section{Pharmacokinetics}

Following a single intravenous dose of samalizumab $\left(100-600 \mathrm{mg} / \mathrm{m}^{2}\right)$, the mean $\mathrm{T}_{\max }$ values across all dose levels ranged from 1.23 to $8.93 \mathrm{~h}$, the mean $\mathrm{T}_{1 / 2}$ for samalizumab increased from $85.1 \mathrm{~h}$ to $537.9 \mathrm{~h}$ (3.5 to 22.4 days), and mean systemic CL showed a decreasing trend in the three highest dose cohorts (Table 3). The mean $\mathrm{V}_{\mathrm{z}}$ did not appear to be dose related. $\mathrm{C}_{\max }$ increased in a dose-proportional manner and $\mathrm{AUC}_{\infty}$ increased in a more than dose-proportional manner. For $C_{\max }$, the $\beta$ value was 1.01 (95\% CI: $0.85-1.17$ ) and for $\mathrm{AUC}_{\infty}$, the $\beta$ value was 2.01 (95\% CI: $1.59-2.42$ ). The serum concentration-time profiles of samalizumab are graphed as the mean serum concentration of samalizumab after the first intravenous administration at the indicated doses. Error bars represent the standard deviation (Additional file 1: Figure S1).

\section{Pharmacodynamics}

The binding of samalizumab to CD200 on peripheral CLL cells was evaluated in 21 of 23 (91\%) CLL patients. 
Mahadevan et al. Journal for ImmunoTherapy of Cancer

(2019) 7:227

Page 5 of 13

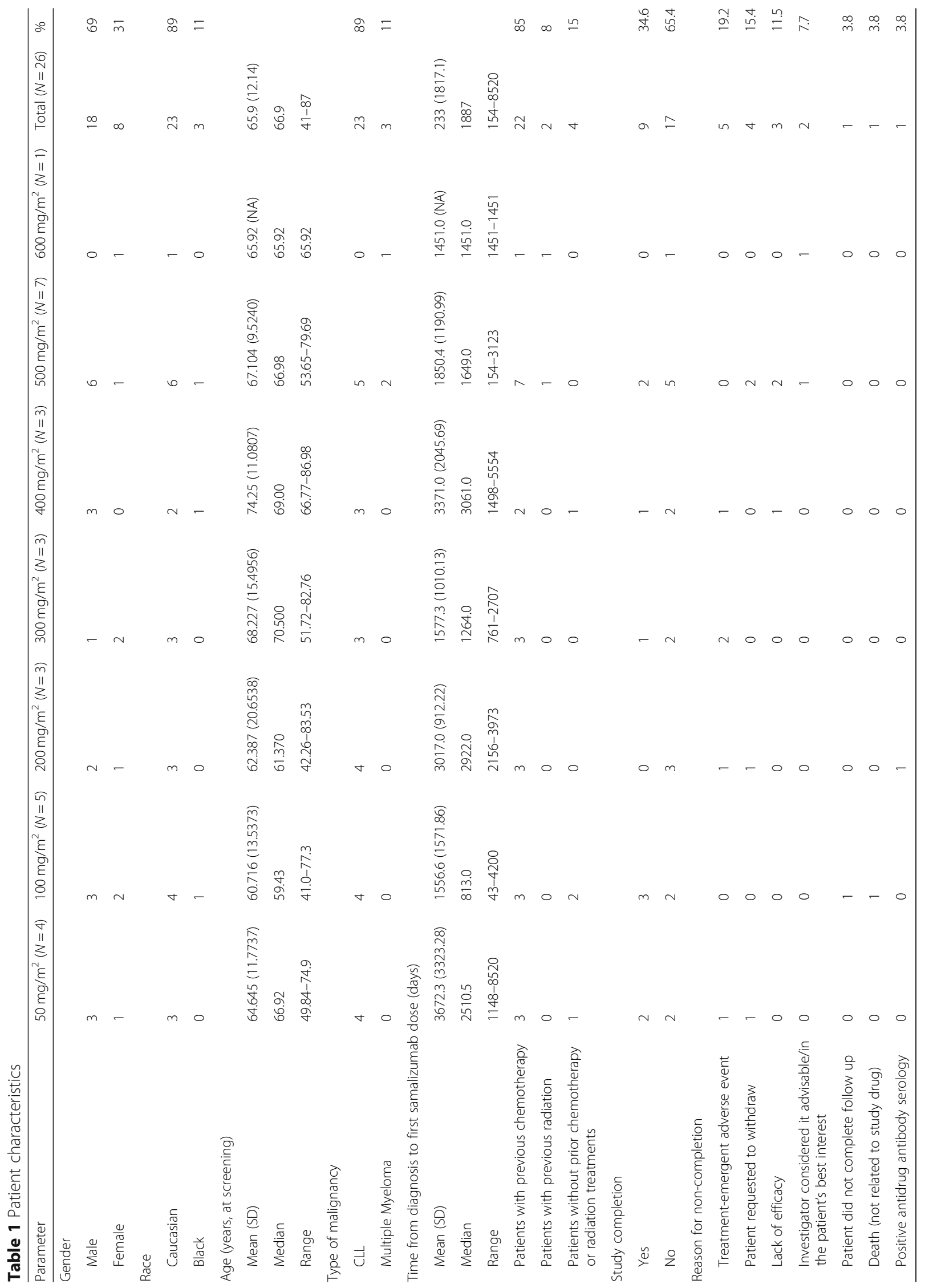


Table 2 Treatment-emergent adverse events (TEAEs) reported in $\geq 5 \%$ patients by organ system

\begin{tabular}{|c|c|c|c|c|c|c|c|c|}
\hline \multirow[t]{2}{*}{ System Organ Class } & \multicolumn{8}{|c|}{ Samalizumab Treatment Group } \\
\hline & $\begin{array}{l}50 \mathrm{mg} / \mathrm{m}^{2} \\
\mathrm{~N}=4\end{array}$ & $\begin{array}{l}100 \mathrm{mg} / \mathrm{m}^{2} \\
N=5\end{array}$ & $\begin{array}{l}200 \mathrm{mg} / \mathrm{m}^{2} \\
N=3\end{array}$ & $\begin{array}{l}300 \mathrm{mg} / \mathrm{m} \\
\mathrm{N}=3\end{array}$ & $\begin{array}{l}400 \mathrm{mg} / \mathrm{m}^{2} \\
\mathrm{~N}=3\end{array}$ & $\begin{array}{l}500 \mathrm{mg} / \mathrm{m}^{2} \\
N=7\end{array}$ & $\begin{array}{l}600 \mathrm{mg} / \mathrm{m}^{2} \\
N=1\end{array}$ & $\begin{array}{l}\text { Overall } \\
N=26\end{array}$ \\
\hline $\begin{array}{l}\text { General Disorders and } \\
\text { Administration Sites }\end{array}$ & & & & & & & & $11(42)$ \\
\hline Fatigue & $1(25)$ & - & $1(33)$ & $3(100)$ & - & $1(14)$ & - & \\
\hline Peripheral coldness & $1(25)$ & - & - & - & - & - & - & \\
\hline Pyrexia & - & - & - & - & - & $1(14)$ & - & \\
\hline Chills & - & - & - & - & - & $1(14)$ & - & \\
\hline Edema & - & - & - & $2(67)$ & - & - & - & \\
\hline Skin and Subcutaneous Tissue & & & & & & & & $9(35)$ \\
\hline Erythema & - & - & - & $1(33)$ & - & - & - & \\
\hline Night sweats & - & - & - & - & - & $1(14)$ & - & \\
\hline Pruritus & $1(25)$ & $1(20)$ & - & - & - & - & - & \\
\hline Rash & $1(25)$ & $1(20)$ & $1(33)$ & $1(33)$ & - & - & - & \\
\hline Urticaria & $1(25)$ & - & - & - & - & - & - & \\
\hline Gastrointestinal & & & & & & & & $5(19)$ \\
\hline Abdominal distension & - & - & - & $1(33)$ & - & - & - & \\
\hline Abdominal Pain & - & - & - & $2(67)$ & - & - & - & \\
\hline Diarrhea & $1(25)$ & $1(20)$ & - & - & - & - & - & \\
\hline Infections and Infestations & & & & & & & & $4(15)$ \\
\hline Upper Respiratory Tract Infection & - & $1(20)$ & - & - & $1(33)$ & $1(14)$ & - & \\
\hline Abscess & - & - & - & $1(33)$ & - & - & - & \\
\hline $\begin{array}{l}\text { Musculoskeletal and Connective } \\
\text { Tissue }\end{array}$ & & & & & & & & $4(15)$ \\
\hline Arthralgia & - & - & - & $1(33)$ & - & - & - & \\
\hline Muscular weakness & $1(25)$ & - & - & - & - & - & - & \\
\hline Myalgia & $1(25)$ & - & - & - & - & - & - & \\
\hline Stiffness & - & $1(20)$ & - & - & - & - & - & \\
\hline Nervous System & & & & & & & & $3(12)$ \\
\hline Dizziness & - & - & - & $1(33)$ & - & - & - & \\
\hline Headache & - & - & - & - & - & $1(14)$ & - & \\
\hline Paraesthesia & - & - & - & $1(33)$ & - & - & - & \\
\hline Blood and Lymphatic System & & & & & & & & $7(27)$ \\
\hline Anemia & - & - & - & $1(33)$ & $1(33)$ & - & - & \\
\hline Neutropenia & $2(50)$ & - & - & $1(33)$ & $1(33)$ & - & - & \\
\hline Thrombocytopenia & - & - & - & - & $1(33)$ & - & - & \\
\hline Eye & & & & & & & & $6(23)$ \\
\hline Eye pain & $1(25)$ & - & - & - & - & $1(14)$ & - & \\
\hline Night blindness & $1(25)$ & - & - & - & - & - & - & \\
\hline Photophobia & $1(25)$ & - & - & - & - & $1(14)$ & - & \\
\hline Reduced visual acuity & $1(25)$ & - & - & - & - & - & - & \\
\hline Laboratory & - & & - & & - & - & - & $2(8)$ \\
\hline Increased blood viscosity & & - & & $1(33)$ & & - & & \\
\hline Decreased platelets & & $1(20)$ & & & & - & & \\
\hline
\end{tabular}


Table 2 Treatment-emergent adverse events (TEAEs) reported in $\geq 5 \%$ patients by organ system (Continued)

\begin{tabular}{|c|c|c|c|c|c|c|c|c|}
\hline \multirow[t]{2}{*}{ System Organ Class } & \multicolumn{8}{|c|}{ Samalizumab Treatment Group } \\
\hline & $\begin{array}{l}50 \mathrm{mg} / \mathrm{m}^{2} \\
\mathrm{~N}=4\end{array}$ & $\begin{array}{l}100 \mathrm{mg} / \mathrm{m}^{2} \\
N=5\end{array}$ & $\begin{array}{l}200 \mathrm{mg} / \mathrm{m}^{2} \\
N=3\end{array}$ & $\begin{array}{l}300 \mathrm{mg} / \mathrm{m} \\
N=3\end{array}$ & $\begin{array}{l}400 \mathrm{mg} / \mathrm{m}^{2} \\
N=3\end{array}$ & $\begin{array}{l}500 \mathrm{mg} / \mathrm{m}^{2} \\
N=7\end{array}$ & $\begin{array}{l}600 \mathrm{mg} / \mathrm{m}^{2} \\
\mathrm{~N}=1\end{array}$ & $\begin{array}{l}\text { Overall } \\
N=26\end{array}$ \\
\hline Respiratory, Thoracic and Mediastinal & & & & & & & & $4(15)$ \\
\hline Cough & - & - & - & - & - & $1(14)$ & - & \\
\hline Dyspnea & - & - & - & $1(33)$ & - & $1(14)$ & - & \\
\hline Pulmonary edema & _- & - & _- & _- & _- & $1(14)$ & _ & \\
\hline
\end{tabular}

Values in parentheses are the percentage of patients

Only one occurrence per patient counted for each category

"-" indicates zero

Two patients were not evaluable because of insufficient circulating CLL cells and high background level staining precluding reliable analysis. Despite considerable interpatient variability in baseline peripheral CLL counts (range $0.8-90.7 \%$ ), nearly all CLL cells (85 to 100\%) were CD200+, although there was wide interpatient variation in the intensity of CD200 expression on CLL cells.

On day 1 after dosing, bound samalizumab was detected on peripheral CD200+ CLL cells in 16 of 21 (76\%) evaluable patients. Increased binding was observed at higher doses $\left(200-500 \mathrm{mg} / \mathrm{m}^{2}\right)$. The range of frequencies of CLL cells with bound samalizumab on day 1 , and the density of bound samalizumab MFI by dose cohort are summarized in Table 4. Down-regulation of CD200 expression on CLL cells was observed in 18 of 21 patients (86\%) after samalizumab dosing (Fig. 1a). The density of CD200 expression (MFI) on day 1 was reduced from baseline by $6.8-74.3 \%$. A dose-dependent reduction in CD200 expression on CLL cells was observed after multiple dosing: transient reductions in CD200 expression were generally observed in patients treated with lower doses $\left(50-200 \mathrm{mg} / \mathrm{m}^{2}\right)$, whereas sustained reductions were seen in 18 of 21 evaluable patients (86\%) patients receiving higher doses $\left(300-500 \mathrm{mg} / \mathrm{m}^{2}\right)$.

The percent change from baseline in peripheral CD200+ CD4+ T cells for all evaluable CLL and MM patients is shown in Fig. 1b. Of the 26 enrolled patients, 21 (81\%) were evaluated; four patients with CLL and one with MM were not evaluable due to insufficient circulating immune cells.
By day 1 after samalizumab dosing, all evaluable patients showed a decrease in the frequency of peripheral CD200+ CD4+ T cells (range of $-15.6 \%$ to $-85.3 \%$ from baseline). Of 17 patients who received $>1$ dose of samalizumab, 16 (94\%) continued to show reductions in CD200+ CD4+ T cell frequencies in response to dosing. Similar to the reduction in CD200 expression observed on CLL cells, a dosedependent reduction in the frequencies of peripheral CD200+ CD4+ T cells was also observed, with transient responses at low doses $\left(50-200 \mathrm{mg} / \mathrm{m}^{2}\right)$ and sustained responses at higher doses $\left(300-500 \mathrm{mg} / \mathrm{m}^{2}\right)$.

With the exception of CD200+ CD4+ T cells, no apparent dose-dependent effect of samalizumab on other $\mathrm{T}$-cell subsets was found. Changes in the frequencies of CD3+ cells or total CD4+ cells (regardless of CD200 expression) revealed considerable inter-patient variability across and within cohorts, with no clear trends discernable. Cell counts of CD8 + cells, activated T cells, and $\mathrm{T}_{\text {regs, }}$, at baseline or during treatment, were too low to provide reliable results. A notable exception is Patient $\# 102-502$, treated at the $400 \mathrm{mg} / \mathrm{m}^{2}$ dose, who had sufficient immune cells for analysis; this patient is discussed in the Additional file 1 (pages 8-10). Patients with MM received up to three doses of samalizumab and showed little change in $\mathrm{T}$-cell subsets.

In one patient, a transient increase in peripheral B-CLL count, absolute lymphocyte count and white cell count was observed following initial samalizumab treatment (Additional file 1: Figure S2). The observed binding to

Table 3 Summary of samalizumab PK parameters

\begin{tabular}{llllllll}
\hline Dose & No. of patients & $\begin{array}{l}T_{\max } \\
(\mathrm{h})\end{array}$ & $\begin{array}{l}\mathrm{C}_{\max } \\
(\mu \mathrm{g} / \mathrm{mL})\end{array}$ & $\begin{array}{l}\mathrm{AUC} \mathrm{C}_{\infty} \\
(\mu \mathrm{g} \cdot \mathrm{h} / \mathrm{mL})\end{array}$ & $\begin{array}{l}\mathrm{T}_{1 / 2} \\
(\mathrm{~h})\end{array}$ & $\begin{array}{l}\mathrm{CL} \\
(\mathrm{mL} / \mathrm{h})\end{array}$ & $\begin{array}{l}\mathrm{V}_{z} \\
(\mathrm{~mL})\end{array}$ \\
\hline $100 \mathrm{mg} / \mathrm{m}^{2}$ & 5 & $2.21 \pm 3.25$ & $38.9 \pm 4.75$ & $2792 \pm 2227$ & $85.1 \pm 60.9$ & $101 \pm 67.5$ & $8246 \pm 1499$ \\
$200 \mathrm{mg} / \mathrm{m}^{2}$ & 3 & $1.23 \pm 0.09$ & $90.2 \pm 10.6$ & $11,957 \pm 6599$ & $107 \pm 45.2$ & $36.3 \pm 14.9$ & $4943 \pm 469$ \\
$300 \mathrm{mg} / \mathrm{m}^{2}$ & 3 & $4.71 \pm 4.65$ & $109 \pm 42.7$ & $36,636 \pm 11,540$ & $371 \pm 48.9$ & $16.9 \pm 4.15$ & $9186 \pm 3215$ \\
$400 \mathrm{mg} / \mathrm{m}^{2}$ & 3 & $8.93 \pm 11.1$ & $135 \pm 37.8$ & $37,679 \pm 7219$ & $245 \pm 33.9$ & $21.3 \pm 4.61$ & $7391 \pm 897$ \\
$500 \mathrm{mg} / \mathrm{m}^{2}$ & 7 & $3.87 \pm 1.85$ & $211 \pm 44.9$ & $62,898 \pm 24,222$ & $365 \pm 172$ & $19.5 \pm 10.4$ & $8490 \pm 1715$ \\
$600 \mathrm{mg} / \mathrm{m}^{2}$ & 1 & 3.08 & 288 & 134,629 & 538 & 7.58 & 5880 \\
\hline
\end{tabular}

Values are presented as Mean \pm SD. The samalizumab serum concentration assay had a lower limit of quantification of $3.70 \mu \mathrm{g} / \mathrm{mL}$ and the standard curve ranged from 3.7 to $100 \mu \mathrm{g} / \mathrm{mL}$ Assay precision was 1 to $18 \%$ and accuracy was 93.2 to $127.8 \%$ (Mean \% of recovery) 
Table 4 Samalizumab bound to CD200+ CLL cells by cohort

\begin{tabular}{|c|c|c|c|c|}
\hline \multirow[t]{2}{*}{ Samalizumab Cohort } & \multicolumn{2}{|c|}{ CLL cells bound by samalizumab (\%) } & \multicolumn{2}{|c|}{ Density of bound samalizumab (MFI) } \\
\hline & Pre-dose & Day 1 & Pre-dose & Day 1 \\
\hline $50 \mathrm{mg} / \mathrm{m}^{2}(n=4)$ & $0.3-0.7$ & $1.1-3.3$ & $1.9-3.1$ & $3.3-4.1$ \\
\hline $100 \mathrm{mg} / \mathrm{m}^{2}(n=5)$ & $0.2-2.4$ & $0.2-9.5$ & $3.5-5.6$ & $5.0-11.1$ \\
\hline $200 \mathrm{mg} / \mathrm{m}^{2}(n=2)$ & $0.3-0.7$ & $27.8-29.6$ & $3.2-3.3$ & $16.6-19.3$ \\
\hline $300 \mathrm{mg} / \mathrm{m}^{2}(n=2)$ & $0.5-0.7$ & $5-28.6$ & $1.7-3.0$ & $5.6-16.8$ \\
\hline $400 \mathrm{mg} / \mathrm{m}^{2}(n=3)$ & $1.1-5.7$ & $1.7-71.3$ & $1.7-3.4$ & $4.6-26.6$ \\
\hline $500 \mathrm{mg} / \mathrm{m}^{2}(n=5)$ & $0.5-2.1$ & $1-47.0$ & $1-3.7$ & $1.9-17.6$ \\
\hline
\end{tabular}

Binding of samalizumab to CD200 on circulating CLL cells was evaluated by multi-parametric flow cytometry using a fluorescently-labeled monoclonal antibody specific for samalizumab (7B8) together with a second anti-CD200 antibody (IB2) specific for an epitope of CD200 distinct from the binding site of samalizumab

CD200+ B-CLL cells and the reduction in CD200 expression indicates that samalizumab is binding to and blocking its intended target, the immunoregulatory molecule CD200. However, even at doses of $500 \mathrm{mg} / \mathrm{m}^{2}$, neither maximal saturation of CD200 binding nor maximal sustained decreases in CD200 expression on the B-CLL target cells was achieved. Changes from Baseline in absolute lymphocyte count and circulating B-CLL cells were found to trend similarly: an overall reduction in peripheral B-CLL cells after samalizumab dosing paralleled the reduction in absolute lymphocyte count. In 14/23 (56.5\%) patients, this increase was followed by a reduction in both peripheral CLL cells and absolute lymphocyte count with multiple samalizumab doses (\% decrease 0.5 to $50 \%$ ).

Detectable levels of Th1 and Th2 cytokines (IFN- $\gamma$, IL2 , IL-10, IL-12p70 and TNF- $\alpha$ ) were observed following the first dose, but levels were neither sustained nor associated with clinical symptoms (data not shown).

\section{Response to therapy}

The ORR for CLL patients was 4\% (1 of 23) with this conservative dosing schedule. Sixteen CLL patients (70\%) achieved SD, and five patients (22\%) had PD. One patient was not evaluable and one patient had a PR that was confirmed at cycle 12 (Patient \#102-502; see case study in Additional file 1 - pages 3-5 and 8-10). Patient \#102-502 was a newly diagnosed with Rai stage IV and was treated at the $400 \mathrm{mg} / \mathrm{m}^{2}$ dose. A reduction in CD200 expression on CLL cells was associated with a transient increase in peripheral CLL cells followed by a progressive reduction peripheral CLL cells (Fig. S2), CD200+ CD4+ T cells and $\mathrm{T}_{\mathrm{REG}} \mathrm{S}$. In contrast, CD8+ T-cells increased indicating an anti-tumor immune response (Additional file 1: Figure S3). Reduced CD200 expression on CLL cells paralleled a reduction in bulky lymphadenopathy (Additional file 1: Figure S4). One patient, maintained SD through cycle $18\left(300 \mathrm{mg} / \mathrm{m}^{2}\right)$ and two patients maintained a SD through cycle $6\left(500 \mathrm{mg} / \mathrm{m}^{2}\right)$ when the study was terminated. All 3 MM patients had PD.

Of the 22 patients whose primary target lesions were measured by CT scans at baseline and at least one subsequent scan after dosing with samalizumab, 14 (64\%) had a decrease in tumor burden post-dosing. Twelve of these patients were from all dose level cohorts and had a maximum decrease in lymphadenopathy ranging from 3.3 to $28.7 \%$. Two patients had a $>50 \%$ reduction in the total amount of lymphadenopathy: these patients were from the two highest dose cohorts (400 and $500 \mathrm{mg} / \mathrm{m}^{2}$ ) and had maximum decreases in lymphadenopathy of 63.4 and $73.7 \%$, respectively. A 30\% decrease in total lymphadenopathy was the cut-off below which lymph node regression was considered a clinically significant improvement. The maximum change in lymphadenopathy in individual patients is shown in Fig. 2.

Eight patients from all dose level cohorts had a maximum increase in lymphadenopathy (range: 2.8 to $118 \%$ ). Two of these patients had a $>50 \%$ maximum increase in lymphadenopathy, a cut-off above which lymph node enlargement represents progressive disease.

Twenty of the 22 patients (91\%) showed a decrease in the size of at least a single lesion. Ten (45\%) had a maximum reduction $>40 \%$ and five $(23 \%)$ had $>50 \%$ reduction. The reductions in individual lesions did not always correlate with a similar reduction in the sum of the bi-dimensional products of target lesions at the same time point. Eight patients (36\%) had an increase in the sum of products of bi-dimensional target lesions at the time they experienced a maximum reduction in a single lesion (Table 5).

\section{Discussion}

Although promising novel therapies have recently become available, the majority of patients with CLL and MM will ultimately relapse or become refractory to currently available therapeutic regimens, and the only known curative therapy for CLL and MM is stem cell transplantation, with its associated high morbidity and mortality [43, 44]. Blockade of the CD200-CD200R immune checkpoint using a therapeutic anti-CD200 mAb was hypothesized to restore and/or enhance tumor cell recognition and CTL mediated anti-tumor responses in advanced CLL and MM patients with limited therapeutic options. Samalizumab is a novel, 

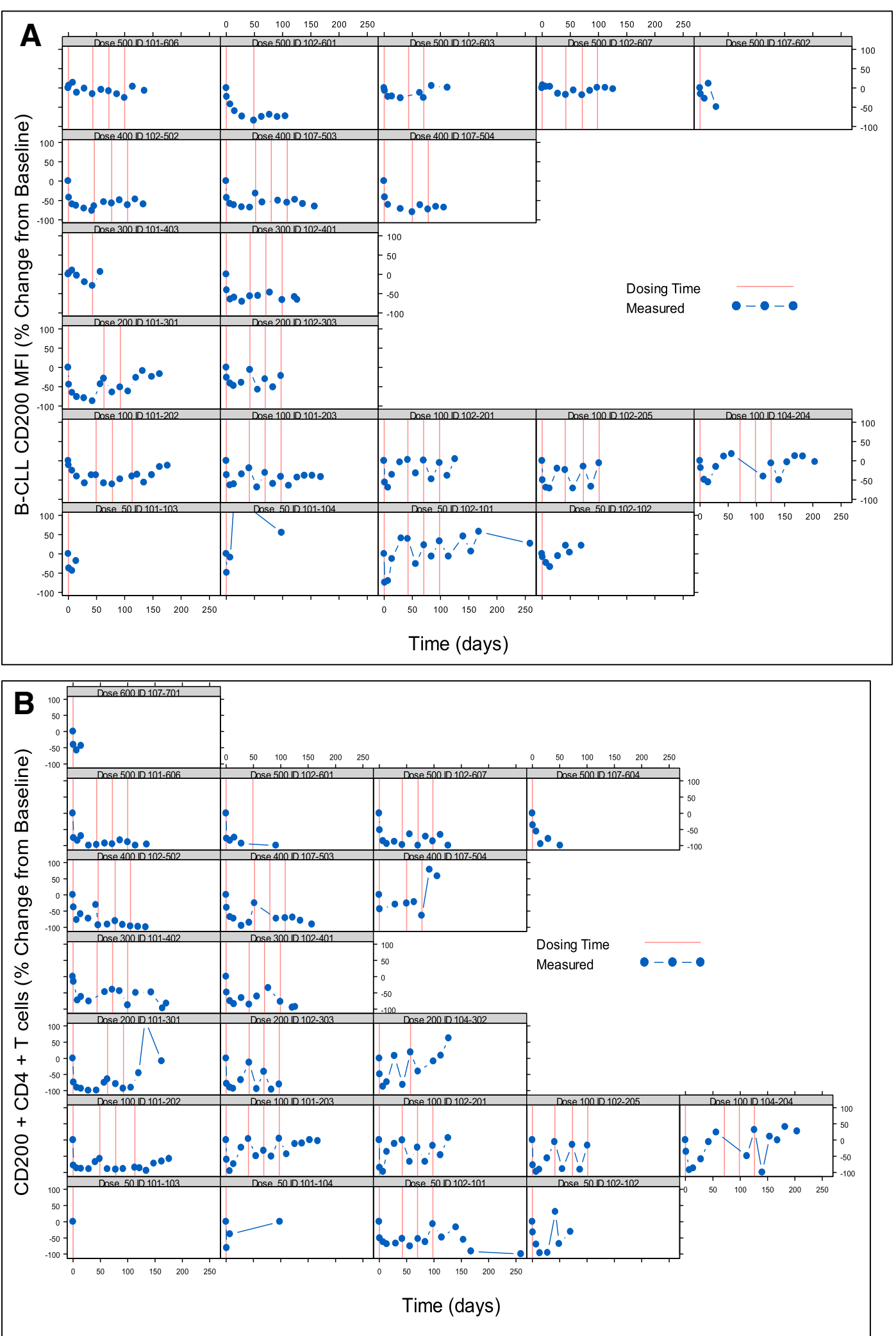

Fig. 1 Each panel displays data for a single patient (indicated at the top of each graph) at baseline (Day 0) and after samalizumab dosing at the indicated time points. For simplicity, no more than the first 4 dosing cycles are shown. a. Percent change from baseline in CLL CD200 expression (mean channel fluorescence (MFI)) in CLL patients. b. Percent change from baseline in CD200+ CD4+ T cells (\%) in CLL and MM patients 


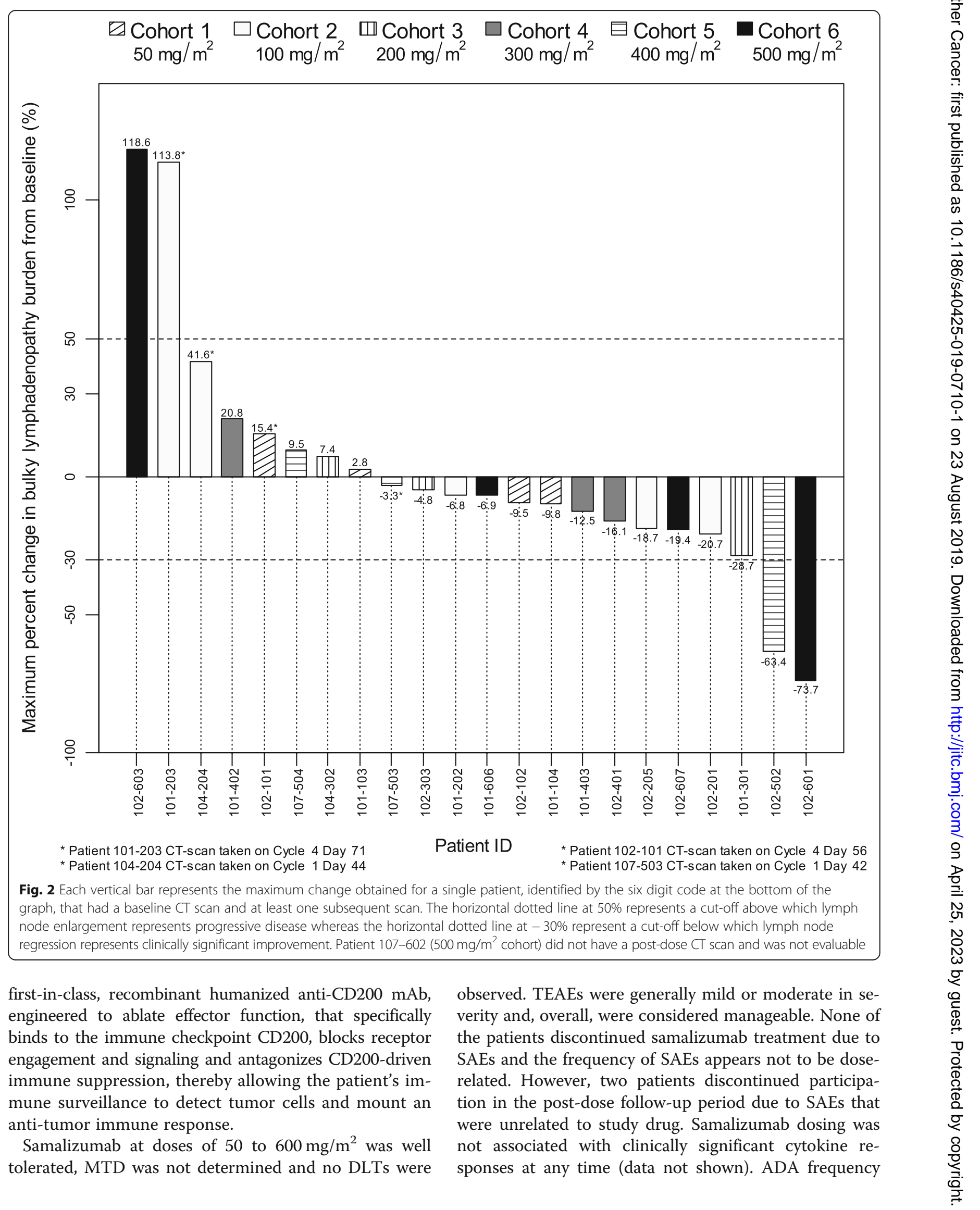


Table 5 Maximum reduction in the sum of lesions and a single lesion after samalizumab dosing

\begin{tabular}{|c|c|c|c|c|c|}
\hline \multirow{2}{*}{$\begin{array}{l}\text { Samalizumab } \\
\text { Treatment Group }\end{array}$} & \multirow[t]{2}{*}{ Patient ID } & \multicolumn{2}{|c|}{ Single Lesion ${ }^{\mathrm{b}}$} & \multicolumn{2}{|c|}{ Sum of Lesions ${ }^{b}$} \\
\hline & & \% Change & Cycle Day & \% Change & Cycle Day \\
\hline \multirow[t]{4}{*}{$50 \mathrm{mg} / \mathrm{m}^{2}(\mathrm{~N}=4)$} & $101-103$ & -3.45 & C1 D28 & 2.77 & C1 D28 \\
\hline & $101-104$ & -45.29 & C1 D77 & -9.8 & C1 D35 \\
\hline & $102-101$ & -19.75 & C4 D16 & 4.32 & C4 D16 \\
\hline & $102-102$ & -9.77 & C1 D35 & -9.46 & C1 D35 \\
\hline \multirow[t]{4}{*}{$100 \mathrm{mg} / \mathrm{m}^{2}(N=4)^{a}$} & $101-202$ & -37.78 & C4 D0 & -6.83 & C4 D0 \\
\hline & $101-203$ & -11.54 & C4 D0 & 7.0 & C1 D28 \\
\hline & $102-201$ & -95.31 & C4 D0 & -20.7 & C4 D0 \\
\hline & $102-205$ & -41.36 & C3 D26 & -18.7 & C3 D26 \\
\hline \multirow[t]{2}{*}{$200 \mathrm{mg} / \mathrm{m}^{2}(N=2)^{a}$} & $101-301$ & -48.67 & C1 D28 & -28.7 & C1 D28 \\
\hline & $102-303$ & -42.05 & C3 D21 & -4.75 & C3 D21 \\
\hline \multirow[t]{3}{*}{$300 \mathrm{mg} / \mathrm{m}^{2}(N=3)$} & $101-402$ & -14.29 & C4 D43 & 8.3 & C4 D43 \\
\hline & $101-403$ & -23.81 & C1 D29 & -12.5 & C1 D29 \\
\hline & $102-401$ & -58.73 & C1 D35 & -16.1 & C16 D1 \\
\hline \multirow[t]{3}{*}{$400 \mathrm{mg} / \mathrm{m}^{2}(\mathrm{~N}=3)$} & $102-502$ & -87.02 & C13 D35 & -63.4 & C13 D35 \\
\hline & $107-503$ & -54.55 & C4 D27 & -3.34 & C1 D42 \\
\hline & $107-504$ & -29.34 & C1 D29 & 9.52 & C1 D29 \\
\hline \multirow[t]{4}{*}{$500 \mathrm{mg} / \mathrm{m}^{2}(\mathrm{~N}=4)^{\mathrm{a}}$} & $101-606$ & -48.15 & C6 D0 & -6.91 & C6 D0 \\
\hline & $102-601$ & -86.36 & C2 D28 & -73.7 & C2 D28 \\
\hline & $102-603$ & -5.13 & C1 D25 & 1.84 & C1 D25 \\
\hline & $102-607$ & -37.36 & C1 D28 & -19.4 & C1 D28 \\
\hline
\end{tabular}

${ }^{a}$ Patient $107-602$ (500 mg/m² cohort) did not have a post-dose CT scan and was not evaluable; Patients $104-204$ (100 mg/m ${ }^{2}$ cohort) and $104-302$ (200 mg/m ${ }^{2}$ cohort) had no reduction in any of their target lesions and are not included

${ }^{b}$ Maximum reduction for a single lesion (product of bi-dimensional tumor measurement) and maximum reduction for sum of lesions (sum of the products of bidimensional tumor measurements) are presented as a \% Change from baseline on the indicated Cycle and Day

was consistent with that in literature reports of other therapeutic mAbs $[45,46]$.

The mean $\mathrm{T}_{1 / 2}$ for samalizumab increased with increasing doses $\left(100 \mathrm{mg} / \mathrm{m}^{2}-600 \mathrm{mg} / \mathrm{m}^{2}\right)$. The high clearance of samalizumab at low doses likely represents saturation binding to membrane-associated CD200 surface antigen. At higher doses, antibody clearance is likely due to nonspecific elimination through the cells of the reticuloendothelial system [47]. These findings are consistent with those of other therapeutic mAbs reported in the literature [48].

Samalizumab binding dampens CD200 overexpression on CLL cells in a dose-dependent manner, and the reduction in CD200 expression is sustained at higher doses $\left(300-500 \mathrm{mg} / \mathrm{m}^{2}\right)$. However, it is apparent from these early data that the concentrations of samalizumab achieved in this phase I study were insufficient to completely saturate cell-surface CD200 on the CLL cells. The PK and PD assays incorporated in this study may provide a strategy to guide optimal dosing in future trials. Sustained decreases in CD200 expression on peripheral CD200+ CD4+ T cells (reduction in the percentage of CD200+ CD4+ T cells) is observed in CLL and MM patients at higher doses $\left(300-600 \mathrm{mg} / \mathrm{m}^{2}\right)$. No other dose-dependent changes in
T-cell subsets were consistently observed, although one patient with no prior chemotherapy demonstrated the predicted immunomodulatory changes following multiple doses of samalizumab: increases in frequencies of activated $\mathrm{T}$ cells and $\mathrm{CD} 8+\mathrm{T}$ cells during prolonged samalizumab treatment, with concomitant reduction of $\mathrm{T}_{\text {REGs }}$ (Additional file 1 pages $3-5$ and 8-10).

The clinical responses reported support the study's central hypothesis that blockade of the immune inhibitory ligand CD200 by samalizumab promotes anti-tumor activity: serial CT scans revealed that more than half (64\%) of evaluable CLL patients had reductions in tumor burden, with two patients having $>50 \%$ reduction. Most CLL patients had a decrease in size of at least one lesion, with $22.7 \%$ of CLL patients experiencing a reduction of $>50 \%$ in at least one lesion. However, in 8 patients, 4 of whom had SD, the maximum reductions in a single lesion did not always correlate with the maximum reduction in the sum of the products of all lesions at the same time point. This may represent an immune-modulated response consistent with pseudoprogression [49]. In clinical trials of solid tumors, increases in tumor burden that can precede responses led to novel evaluation 
criteria (immune-related response criteria (irRC)) [49]. An increase in tumor burden prior to response evaluation may reflect either continued tumor growth until a sufficient immune response develops or transient immune-cell infiltrate. Similar patterns of stable disease or improvement after an initial increase in tumor burden have been observed with other immune checkpoint inhibitors such as ipilimumab and anti-PD-1 mAbs [28, 32 , 33]. Although the irRC have been implemented in solid tumors, mechanisms underlying these increases may also apply to lymphadenopathy in B-cell malignancies.

SD was achieved in sixteen CLL patients: one patient received 18 cycles of samalizumab and maintained SD through cycle $18\left(300 \mathrm{mg} / \mathrm{m}^{2}\right)$ and two patients maintained SD through cycle $6\left(500 \mathrm{mg} / \mathrm{m}^{2}\right)$. All 3 patients remained on samalizumab until the trial was concluded. One treatment-naïve Rai Stage IV CLL patient (Patient\# 102-502) who received 13 cycles of samalizumab achieved a durable PR lasting for $>6$ years with no further interventions and is reported to be healthy at the time of this manuscript. This patient may have had a superior clinical response to samalizumab because of his preserved immune function prior to treatment.

\section{Conclusions}

Advances in the understanding of the mechanisms of protective anti-tumor immunity has led to the development of immune checkpoint therapy with mAbs targeting inhibitory pathways that normally suppress antitumor T-cell immunity and mediate immune tolerance. The findings of this study provide proof-of-concept for targeted inhibition of the immune checkpoint CD200, as samalizumab appears to have provided significant therapeutic benefit to some CLL patients despite a suboptimal dosing schedule. These findings support clinical investigation of samalizumab in CLL and other tumor types with elevated CD200 expression. Further clinical investigation should include additional dosing regimens, including further dose-escalation and more frequent dosing of samalizumab and/or potential combinations with other FDA-approved targeted or immunomodulatory agents.

\section{Additional file}

Additional file 1: Supplemental data on the Phase I Samalizumab trial of CLL and MM. (DOCX $799 \mathrm{~kb}$ )

\section{Acknowledgements}

The authors thank Diane Rensvold, RN and Sandra Kurtin, NP of the University of Arizona Cancer Center, Tucson, AZ for patient care, and Brigid Kane, a medical writer at BioMed Communications, who received funding from Alexion Pharmaceuticals, Inc., for editorial assistance and preparation of manuscript drafts.

\section{Authors' contributions}

DM, MCL, LTH, MP and CF were the principle investigators at each study site and enrolled patients. All co-authors contributed to data collection, analysis and writing of the manuscript. All authors read and approved the final manuscript.

\section{Funding}

The authors express their appreciation to the patients and their families and acknowledge the contributions of Alexion Pharmaceuticals, Inc. The study was sponsored by Alexion Pharmaceuticals, Inc.

Availability of data and materials

Supporting data is available at the journals request.

Ethics approval and consent to participate

All sites consented patients per site IRB and WIRB.

Consent for publication

All authors read the manuscript and agree to publication.

\section{Competing interests}

Academic authors have nothing to disclose. MW, SJF, TU, AK, LL, CLB, and XP are employed by Alexion Pharmaceuticals, Inc.

\section{Author details}

${ }^{1}$ Department of Medicine Division of Hematology/Oncology, University of Arizona Cancer Center, 1515. N. Campbell Avenue, Room 1905, Tucson, AZ 85724, USA. ²Duke University Medical Center, Durham, NC, USA. ${ }^{3}$ Summit Medical Center, MD Anderson Cancer Center, Morristown, NJ, USA. ${ }^{4}$ The West Cancer Center, University of Tennessee, Memphis, TN, USA. ${ }^{5}$ Alexion Pharmaceuticals, Inc., New Haven, CT, USA. ${ }^{6}$ Winship Cancer Institute of Emory University, Atlanta, GA, USA.

Received: 20 May 2019 Accepted: 14 August 2019

Published online: 23 August 2019

\section{References}

1. Barclay AN, Clark MJ, McCaughan GW. Neuronal/lymphoid membrane glycoprotein MRC OX-2 is a member of the immunoglobulin superfamily with a light-chain-like structure. Bioch Soc Symp. 1986;51:149-57.

2. Clark MJ, Gagnon J, Williams AF, Barclay AN. MRC OX-2 antigen: a lymphoid/neuronal membrane glycoprotein with a structure like a single immunoglobulin light chain. EMBO J. 1985;4(1):113-8.

3. Wright GJ, Puklavec MJ, Willis AC, et al. Lymphoid/neuronal cell surface OX2 glycoprotein recognizes a novel receptor on macrophages implicated in the control of their function. Immunity. 2000;13:233-42.

4. Wright GJ, Jones M, Puklavec MJ, Brown MH, Barclay AN. The unusual distribution of the neuronal/lymphoid cell surface CD200 (OX2) glycoprotein is conserved in humans. Immunology. 2001;102(2):173-9.

5. Clark DA, Keil A, Chen Z, Markert U, Manuel J, Gorczynski RM. Placental trophoblast from successful human pregnancies expresses the tolerance signaling molecule, CD200 (OX-2). Am J Reprod Immunol. 2003;50(3):187-95.

6. Webb M, Barclay AN. Localisation of the MRC OX-2 glycoprotein on the surfaces of neurons. J Neurochem. 1984;43(4):1061-7.

7. Barclay AN, Wright GJ, Brooke G, Brown MH. CD200 and membrane protein interactions in the control of myeloid cells. Trends Immunol. 2002;23(6):285-90.

8. Wright GJ, Cherwinski H, Foster-Cuevas M, et al. Characterization of the CD200 receptor family in mice and humans and their interactions with CD200. J Immunol. 2003;171:3034-46.

9. Coles SJ, Wang ECY, Man S, et al. CD200 expression suppresses natural killer cell function and directly inhibits patient anti-tumor response in acute myeloid leukemia. Leukemia. 2011;25(5):792-9.

10. Gorczynski R. CD200:CD200R-mediated regulation of immunity. ISRN Immunol. 2012;2012

11. Holmannova D, Kolackova M, Kondelkova K, Kunes P, Krejsek J, Andrys C. CD200/CD200R paired potent inhibitory molecules regulating immune and inflammatory responses; part I: CD200/CD200R structure, activation, and function. Acta Med (Hradec Kralove). 2012;55(1):12-7.

12. Prendergast GC, Smith C, Thomas S, et al. Indoleamine 2,3-dioxygenase pathways of pathogenic inflammation and immune escape in cancer. Cancer Immunol Immunother. 2014;63(7):721-35. 
13. Rygiel TP, Meyaard L. CD200R signaling in tumor tolerance and inflammation: a tricky balance. Curr Opin Immunol. 2012;24(2):233-8.

14. McWhirter JR, Kretz-Rommel A, Saven A, et al. Antibodies selected from combinatorial libraries block a tumor antigen that plays a key role in immunomodulation. Proc Natl Acad Sci U S A. 2006;103(4):1041-6.

15. Moreaux J, Hose D, Reme T, Jourdan E, Hundemer M, Legouffe E, et al. CD200 is a new prognostic factor in multiple myeloma. Blood. 2006;108(13): 4194-7.

16. Siva A, Xin H, Qin F, Oltean D, Bowdish KS, Kretz-Rommel A. Immune modulation by melanoma and ovarian tumor cells through expression of the immunosuppressive molecule CD200. Cancer Immunol Immunother. 2008;57(7):987-96.

17. Kawasaki BT, Mistree T, Hurt EM, Kalathur M, Farrar WL. Co-expression of the toleragenic glycoprotein, CD200, with markers for cancer stem cells. Biochem Biophys Res Commun. 2007;364(4):778-82.

18. Alapat D, Coviello-Malle JM, Owens R, et al. Diagnostic usefulness and prognostic impact of CD200 expression in lymphoid malignancies and plasma cell myeloma. Am J Clin Pathol. 2012;137(1):93-100.

19. Pardoll DM. The blockade of immune checkpoints in cancer immunotherapy. Nat Rev Cancer. 2012;12:252-64.

20. Norde WJ, Hobo W, van der Voort R, Dolstra H. Coinhibitory molecules in hematologic malignancies: targets for therapeutic intervention. Blood. 2012; 120(4):728-36

21. Ramsay AG. Immune checkpoint blockade immunotherapy to activate antitumour T-cell immunity. Br J Haematol. 2013;162(3):313-25.

22. Pallasch CP, Ulbrich S, Brinker R, Hallek M, Uger RA, Wendtner CM. Disruption of T cell suppression in chronic lymphocytic leukemia by CD200 blockade. Leuk Res. 2009;33(3):460-4.

23. Kretz-Rommel A, Qin F, Dakappagari N, et al. CD200 expression on tumor cells suppresses antitumor immunity: new approaches to cancer immunotherapy. J Immunol. 2007;178(9):5595-605.

24. Gorczynski RM, Chen Z, Diao J, Khatri I, Wong K, Yu K, Behnke J. Breast cancer cell CD200 expression regulates immune response to EMT6 tumor cells in mice. Breast Cancer Res Treat. 2010;123(2):405-15.

25. Osmana AA, Eissaa DG, Moussab MM. CD200 is an independent prognostic factor in multiple myeloma. Egyptian J Haematol. 2014;39:177-81.

26. Kretz-Rommel A, Qin F, Dakappagari N, Cofiell R, Faas SJ, Bowdish KS. Blockade of CD200 in the presence or absence of antibody effector function: implications for anti-CD200 therapy. J Immunol. 2008;180(2):699-705.

27. Ascierto PA, Marincola FM. 2015: the year of anti-PD-1/PD-L1s against melanoma and beyond. EBioMedicine. 2015;2(2):92-3.

28. Hodi FS, O'Day SJ, McDermott DF, et al. Improved survival with ipilimumab in patients with metastatic melanoma. N Engl J Med. 2010;363:711-23.

29. Topalian SL, Hodi FS, Brahmer JR, et al. Safety, activity, and immune correlates of anti-PD-1 antibody in cancer. N Engl J Med. 2012;366(26):2443-54.

30. Garon EB, Rizvi NA, Hui R, et al. Pembrolizumab for the treatment of nonsmall-cell lung cancer. N Engl J Med. 2015;372(21):2018-28.

31. Motzer RJ, Escudier B, McDermott DF, et al. Nivolumab versus everolimus in advanced renal-cell carcinoma. N Engl J Med. 2015;373(19):1803-13.

32. Ribas A, Puzanov I, Dummer R, et al. Pembrolizumab versus investigatorchoice chemotherapy for ipilimumab-refractory melanoma (KEYNOTE-002): a randomised, controlled, phase 2 trial. Lancet Oncol. 2015;16(8):908-18.

33. Robert C, Long GV, Brady B, et al. Nivolumab in previously untreated melanoma without BRAF mutation. N Engl J Med. 2015;372(4):320-30.

34. Robert C, Ribas A, Wolchok JD, et al. Anti-programmed death-receptor-1 treatment with pembrolizumab in ipilimumab-refractory advanced melanoma: a randomised dose-comparison cohort of a phase 1 trial. Lancet. 2014;384(9948):1109-17.

35. Topalian SL, Sznol M, McDermott DF, et al. Survival, durable tumor remission, and long-term safety in patients with advanced melanoma receiving nivolumab. J Clin Oncol. 2014:32(10):1020-30.

36. Larkin J, Chiarion-Sileni V, Gonzalez R, et al. Combined nivolumab and ipilimumab or monotherapy in untreated melanoma. N Engl J Med. 2015; 373(1):23-34.

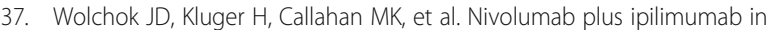
advanced melanoma. N Engl J Med. 2013;369:122-33.

38. Allison JP. Immune checkpoint blockade in cancer therapy. The 2015 Lasker DeBakey clinical medical research award. JAMA. 2015;314(11):1113-4.

39. Jacob JA. Cancer immunotherapy researchers focus on refining checkpoint blockade therapies. JAMA. 2015;314(20):2117-9.
40. Jing W, Gershan JA, Weber J, et al. Combined immune checkpoint protein blockade and low dose whole body irradiation as immunotherapy for myeloma. J Immunother Cancer. 2015;3:2-15.

41. Hallek M, Cheson BD, Catovsky D, Caligaris-Cappio F, Dighiero G. Do"hner H, et al. guidelines for the diagnosis and treatment of chronic lymphocytic leukemia: a report from the international workshop on chronic lymphocytic leukemia updating the National Cancer Institute-working group 1996 guidelines. Blood. 2008;111(12):5446-56.

42. Durie BG, Harousseau JL, Miguel JS, et al. International uniform response criteria for multiple myeloma. Leukemia. 2006;20(9):1467-73.

43. Kumar S, Lacy MQ, Dispenzieri A, et al. High-dose therapy and autologous stem cell transplantation for multiple myeloma poorly responsive to initial therapy. Bone Marrow Transplant. 2004;34:161-7.

44. Dreger $P$, Dohner $H$, Ritgen $M$, et al. Allogeneic stem cell transplantation provides durable disease control in poor-risk chronic lymphocytic leukemia: long-term clinical and MRD results of the GCLLSG CLL3X trial. Blood. 2010; 116:2438-47.

45. Van Walle I, Gansemans Y, Parren PW, Stas P, Lasters I. Immunogenicity screening in protein drug development. Expert Opin Biol Ther. 2007;7(3): 405-18.

46. Harding FA, Stickler MM, Razo J, DuBridge RB. The immunogenicity of humanized and fully human antibodies. MAbs. 2010;2(3):256-65.

47. Tabrizi MA, Tseng CM, Roskos LK. Elimination mechanisms of therapeutic monoclonal antibodies. Drug Discov Today. 2006:11(1-2):81-8.

48. Dirks NL, Meibohm B. Population pharmacokinetics of therapeutic monoclonal antibodies. Clin Pharmacokinet. 2010:49(10):633-59.

49. Wolchok JD, Hoos A, O'Day S, et al. Guidelines for the evaluation of immune therapy activity in solid tumors: immune-related response criteria. Clin Cancer Res. 2009;15(23):7412-20

\section{Publisher's Note}

Springer Nature remains neutral with regard to jurisdictional claims in published maps and institutional affiliations.

Ready to submit your research? Choose BMC and benefit from:

- fast, convenient online submission

- thorough peer review by experienced researchers in your field

- rapid publication on acceptance

- support for research data, including large and complex data types

- gold Open Access which fosters wider collaboration and increased citations

- maximum visibility for your research: over $100 \mathrm{M}$ website views per year

At $\mathrm{BMC}$, research is always in progress.

Learn more biomedcentral.com/submissions 